\title{
MOVIMENTAÇÃO E TRANSFERENCIA DE PACIENTES: ASPECTOS POSTURAIS E ERGONÔMICOS
}

\section{MOVING AND LIFTING PATIENTS: POSTURAL AND ERGONOMIC ASPECTS}

Neusa Maria Costa Alexandre* Maria Marilene Rogante**

\begin{abstract}
ALEXANDRE, N. M. C; ROGANTE, M. M. Movimentação e transferência de pacientes: aspectos posturais e ergonômicos. Rev.Esc.Enf.USP, v. 34, n. 2, p. 165-73, jun. 2000.

\section{RESUMO}

Os procedimentos que envolvem a movimentação e o transporte de pacientes são considerados os mais penosos e perigosos para os trabalhadores de saúde, sendo que a implementação de treinamentos e reciclagem é parte obrigatória de programas de prevenção de lesões músculo-esqueléticas em escolas e instituições de saúde. O presente trabalho descreve orientações básicas e inovadoras sobre esses procedimentos, dentro de uma abordagem ergonômica e com a utilização de materiais auxiliares.
\end{abstract}

PALAVRAS-CHAVE: Ergonomia. Postura. Transporte de pacientes.

\begin{abstract}
The most dangerous and difficult tasks faced by health workers are those procedures involved with lifting and moving patients. Therefore, training and recycling programs in lifting procedures are a compulsory part of programs for the prevention of musculoskeletal disorders in schools and health institutions. The present study presents basic and innovative orientation with an ergonomic approach regarding these procedures, together with the use of devices.
\end{abstract}

KEYWORDS: Ergonomics. Posture. Transportation of patient.

\section{INTRODUÇÃO}

Grande parte das agressões à coluna vertebral em trabalhadores da saúde estão relacionadas a condições ergonômicas inadequadas de mobiliários, posto de trabalho e equipamentos utilizados nas atividades cotidianas, sendo as dores nas costas causadas por traumas crônicos repetitivos, que envolvem muitos outros fatores, além da manipulação de pacientes $2^{\prime} 3^{\prime} 4^{\prime} 15^{\prime} 23$. Dessa forma, as recomendações sobre um aspecto relevante do problema das algias vertebrais, que é a prevenção, têm caminhado em direção a uma abordagem ergonômica.

A literatura tem sugerido a administração de cursos sobre movimentação e transporte de pacientes como uma das estratégias mais importantes para reduzir a incidência de problemas na coluna vertebral entre os trabalhadores da saúde 14,21,24 A utilização de equipamentos especiais e auxílios mecânicos também tem sido indicada para prevenir as dores nas costas 9,26. Atualmente sabe-se que para resolver tais problemas é necessário um amplo estudo do ambiente, dos equipamentos e dos individuos, baseando-se num enfoque ergonômico 11,18,20,23, Assim, as habilidades em movimentação de pacientes devem ser complementadas com o estabelecimento de práticas seguras de trabalho dentro de uma estrutura ergonômica, usando-se, sempre que possivel, materiais e equipamentos auxiliares. O presente trabalho tem por objetivo discutir e descrever as

\footnotetext{
* Enfermeira. Professora Assistente Doutora do Departamento de Enfermagem - Faculdade de Ciências Médicas. UNICAMP

** Enfermeira. Assistente Técnico em Recursos Materiais. Hospital das Clínicas. UNICAMP
} 
técnicas de movimentação e transferência de pacientes dentro de uma estrutura ergonômica e com a utilização de materiais auxiliares que precisam urgentemente ser implementados na realidade brasileira.

\section{MOVIMENTAÇÃO E TRANSPORTE DE PACIENTES}

Os procedimentos que envolvem a movimentação e o transporte de pacientes são considerados os mais penosos e perigosos para os trabalhadores da saúde. Estudiosos da questão defendem que o ensino desses procedimentos deve ser complementado com uma avaliação do local de trabalho e com alternativas para torná-los menos prejudiciais 16,18,23 Um cuidadoso planejamento, antes de se iniciarem esses procedimentos, é essencial e imprescindivel. Dentro deste contexto, desenvolveram-se orientações básicas

e procedimentos que tiveram um suporte teórico na literatura internacional 16,17,22,23.

Considerando-se tais aspectos, dividiu-se esta fase em cinco partes :

\section{cliente \\ 2.1 Avaliação das condições e preparo do}

Inicialmente, deve-se fazer uma avaliação das condições físicas da pessoa que será movimentada, de sua capacidade de colaborar, bem como a observação da presença de soros, sondas e outros equipamentos instalados. Também é importante, para um planejamento cuidadoso do procedimento, uma explicação, ao paciente, do modo como se pretende movê-lo, como pode cooperar, para onde será encaminhado e qual o motivo da locomoção. Vale a pena salientar que o cliente deve ser orientado a ajudar, sempre que for possível, que não deve ser mudado rapidamente de posição e tem que estar usando chinelos ou sapatos com sola antiderrapante. Outro ponto muito importante é que a movimentação e o transporte de obesos precisam ser minuciosamente avaliados e planejados, usandose, sempre que possivel, auxílios mecânicos.

\subsection{Preparo do ambiente e dos equipamentos}

Considerando-se que determinados aspectos ergonômicos do posto de trabalho podem prejudicar atividades ocupacionais, tais como os procedimentos relacionados com movimentação e transporte 5,8,16,19 abordam-se, nessa parte, os principais cuidados que necessitam ser
observados:Verificar se o espaço fisico é adequado para não restringir os movimentos

- Examinar o local e remover os obstáculos

- Observar a disposição do mobiliário

- Obter condições seguras com relação ao piso

- Colocar o suporte de soro ao lado da cama, quando necessário

- Elevar ou abaixar a altura da cama, para ficar no mesmo nivel da maca

- Travar as rodas da cama, maca e cadeira de rodas ou solicitar auxílio adicional

- Adaptar a altura da cama ao trabalhador e ao tipo de procedimento que será realizado

Devem-se, também, utilizar equipamentos auxiliares e adaptar as condições do ambiente a cada paciente em particular. Neste caso, pode ser necessário:

- Colocar barras de apoio em banheiros

- Elevar a altura do vaso sanitário ( compensadores de altura para vasos convencionais )

- Utilizar cadeira de rodas própria para banho ou higiene

\subsection{Preparo da equipe}

Existem algumas orientações, especificamente relacionadas com os principios básicos de mecânica corporal, que devem ser utilizadas pelo pessoal de enfermagem durante a manipulação de pacientes $6,10,11,12,16$

- Deixar os pés afastados e totalmente apoiados no chão

- Trabalhar com segurança e com calma

- Manter as costas eretas

- Usar o peso corporal como um contrapeso ao do paciente

- Flexionar os joelhos em vez de curvar a coluna

- Abaixar a cabeceira da cama ao mover um paciente para cima

- Utilizar movimentos sincrônicos

- Trabalhar o mais próximo possivel do corpo do cliente, que deverá ser erguido ou movido

- Usar uniforme que permita liberdade de movimentos e sapatos apropriados

- Realizar a manipulação de pacientes com a ajuda de, pelo menos, duas pessoas 


\subsection{Movimentação de clientes no leito}

Lembrar que o paciente deve ser estimulado a movimentar-se de uma forma independente, sempre que não existir contra-indicações nesse sentido. Outro ponto que não pode ser esquecido é procurar ter à disposição camas e colchões apropriados, dependendo das condições e necessidades do cliente. O ideal são camas com altura regulável, que possam ser ajustadas, dependendo do procedimento que será realizado 7,16 .

Durante a movimentação, deve-se, sempre que possivel, utilizar elementos auxiliares, tais como: barra tipo trapézio no leito, plástico antiderrapante para os pés, plástico facilitador de movimentos, entre outros.

Neste tópico serão apresentados separa-damente os principais motivos que levam os trabalhadores de saúde a movimentar os clientes no leito:

\subsubsection{Colocar ou retirar comadres}

Quando o paciente pode auxiliar, deve-se utilizar o trapézio, no leito, e solicitar que eleve o quadril, evitando-se assim, a necessidade de erguê-lo (Figura $1)$ :

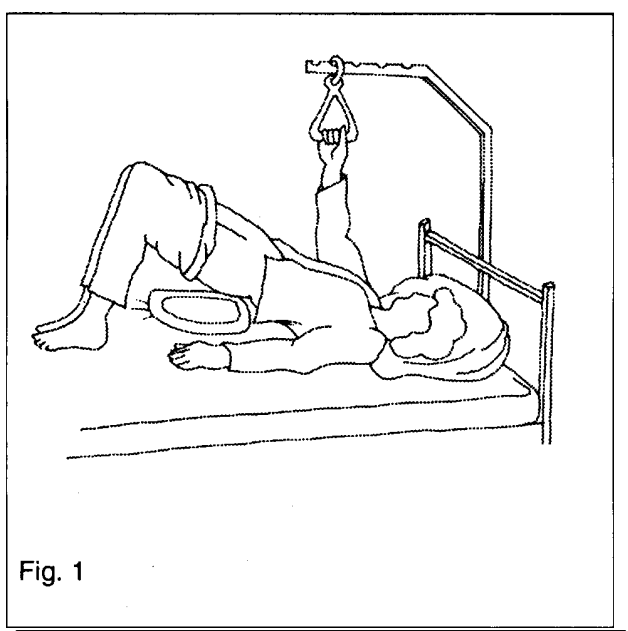

2.4.2 Trazer o cliente para um dos lados da cama

Lembrar que a movimentação no leito deve ser realizada, preferencialmente, por duas pessoas, seguindo-se os seguintes passos (Figura 2):

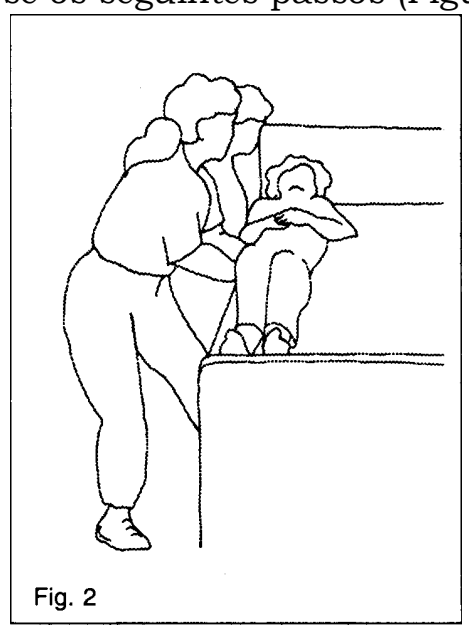

- As duas pessoas devem ficar do mesmo lado da cama, de frente para o paciente

- Permanecer com uma das pernas em frente da outra, com os joelhos e quadris fletidos, trazendo os braços ao nível da cama:

- a primeira pessoa coloca um dos braços sob a cabeça e, o outro, na região lombar

- a segunda pessoa coloca um dos braços também sob a região lombar e, o outro, na região posterior da coxa

- Trazer o paciente, de um modo coordenado, para este lado da cama

Se for necessário mover o paciente sem ajuda, deve-se fazê-lo em etapas, utilizando-se o peso do corpo como um contrapeso e plásticos facilitadores de movimentos.

\subsubsection{Colocar o cliente em decúbito lateral}

Quando o paciente não é obeso, podem-se seguir as seguintes fases (Figura 3):

- Permanecer do lado para o qual você vai virar a pessoa

- Cruzar seu braço e sua perna no sentido em que ele vai ser virado, flexionando o joelho. Observar o posicionamento do outro braço direção

- Fazer o paciente virar a cabeça em sua

- Rolar a pessoa gentilmente, utilizando seu ombro e joelho como alavancas

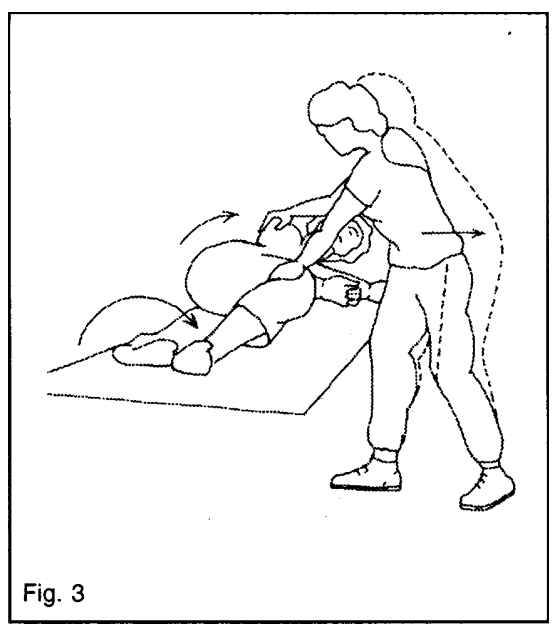

Uma outra forma de realizar esse procedimento é usando-se plásticos deslizantes e resistentes, da seguinte forma (Figura 4):

- Virar o paciente e colocar o plástico sob seu corpo. Voltar o paciente e puxar o plástico

- Ficar no lado oposto ao que o paciente será virado 
- Puxar o plástico, movendo o paciente em sua direção e para a beira da cama. Manter as costas eretas e utilizar o peso do seu corpo

- Elevar o plástico, fazendo o paciente virar cuidadosamente. Manter, no lado oposto da cama, uma grade de proteção

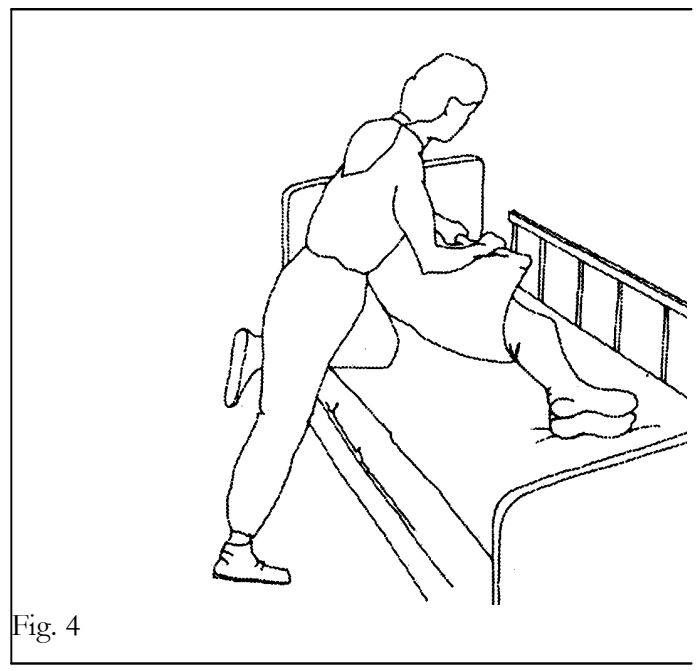

\subsubsection{Movimentar o cliente, em posição supina, para a cabeceira da cama}

Se o paciente tem condições físicas, ele pode mover-se sozinho, com a ajuda de um trapézio. O cliente flexiona os joelhos e dá um impulso, tendo como apoio um plástico antiderrapante sob seus pés (Figura 5b) ou uma pessoa segurando - os (Figura 5a). Pode-se também colocar um plástico deslizante sob as costas e a cabeça do paciente

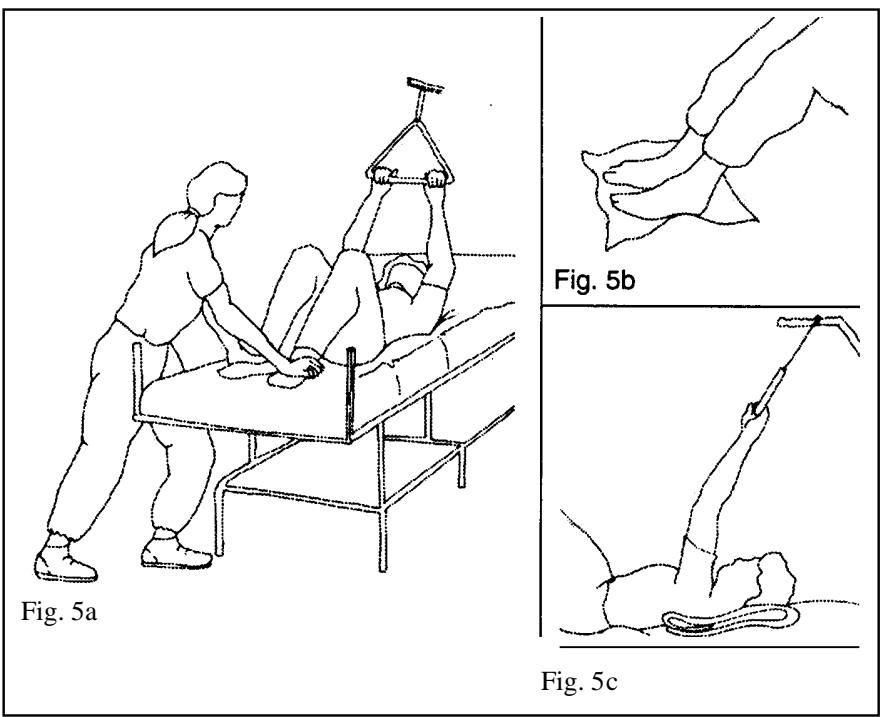

(Figura 5c).

Uma outra maneira de movimentação independente é colocar um plástico deslizante sob o corpo do paciente e pedir que ele realize o mesmo impulso com os pés (Figura 6).

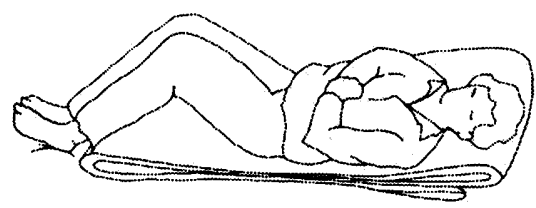

Fig. 6

Quando o paciente não pode colaborar, uma alternativa é seguir os seguintes passos (Figura 7):

- Deixar a cama em posição horizontal

- Colocar um travesseiro na cabeceira da cama

- Colocar um lençol ou plástico deslizante sob o corpo do paciente

- Permanecer duas pessoas, uma de cada lado do leito, e olhando em direção dos pés da cama

- Segurar firmemente no lençol ou plástico e, num movimento ritmado, movimentar o paciente

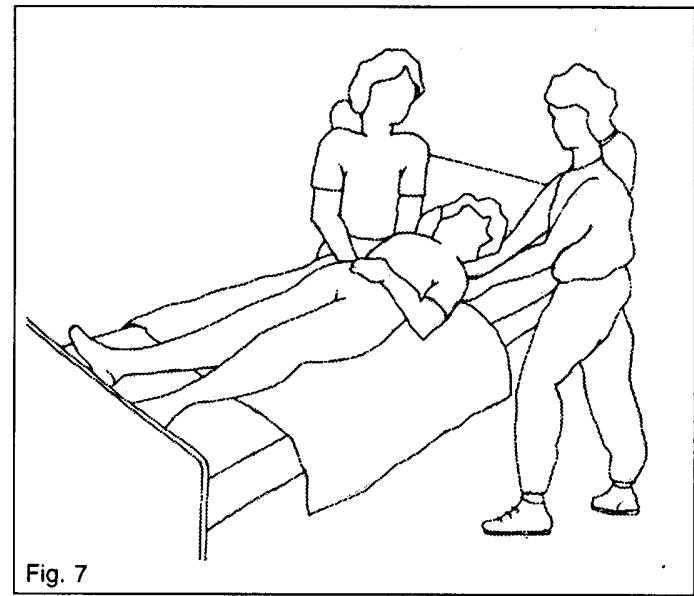

Se a altura da cama for regulável, pode-se proceder da seguinte maneira (Figura 8):

- Abaixar a altura da cama de tal forma que os trabalhadores de enfermagem possam colocar um joelho na cama e manter a outra perna firmemente no chão

- Segurar o plástico e, de uma forma coordenada, sentar sobre seus calcanhares, movendo ao mesmo tempo o cliente

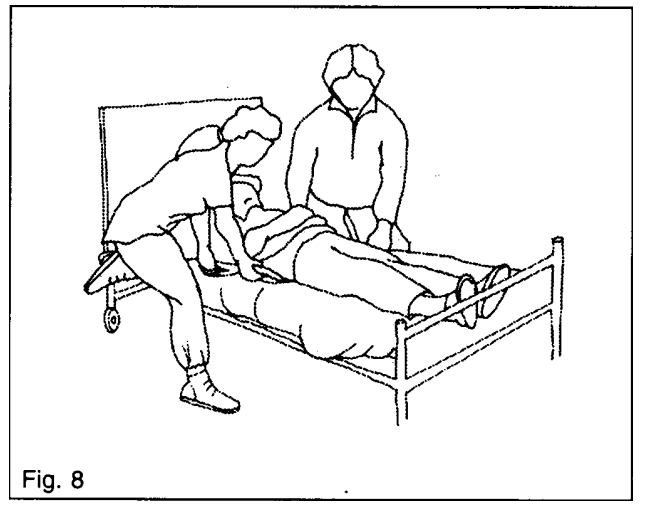

Rev. Esc. Enf. USP, v.34, n.2, p. 165-73, jun. 2000 


\subsubsection{Movimentar o cliente em posição sentada para a cabeceira da cama}

O paciente deve ser encorajado a movimentar-se sozinho, com a ajuda de um plástico facilitador de movimentos. Neste caso, o paciente fica sentado sobre o plástico, podendo deslizar com o auxílio de blocos de mão antiderrapantes (Figura 9).

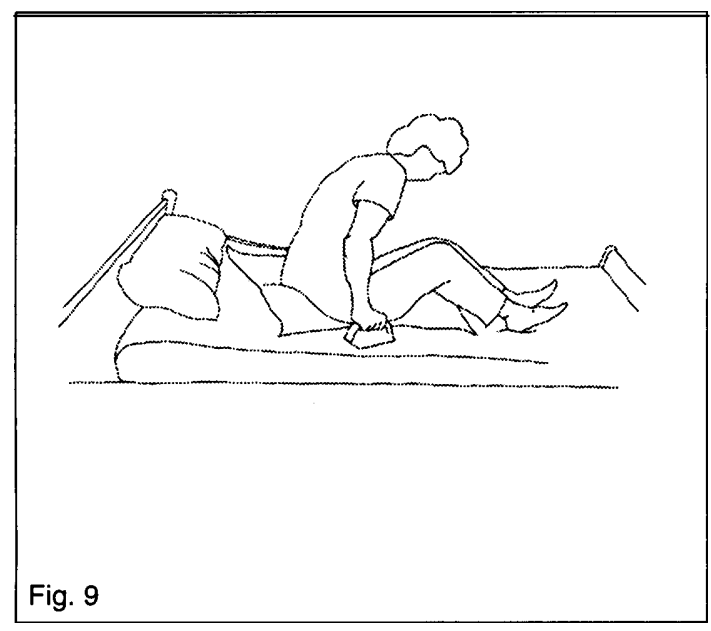

Ele pode, também, receber a ajuda de uma pessoa, que segura seus pés, estando suas pernas flexionadas. Neste caso, o cliente apóia uma mão de cada lado do corpo e ele próprio dá um impulso, ao endireitar as pernas (Figura 10).

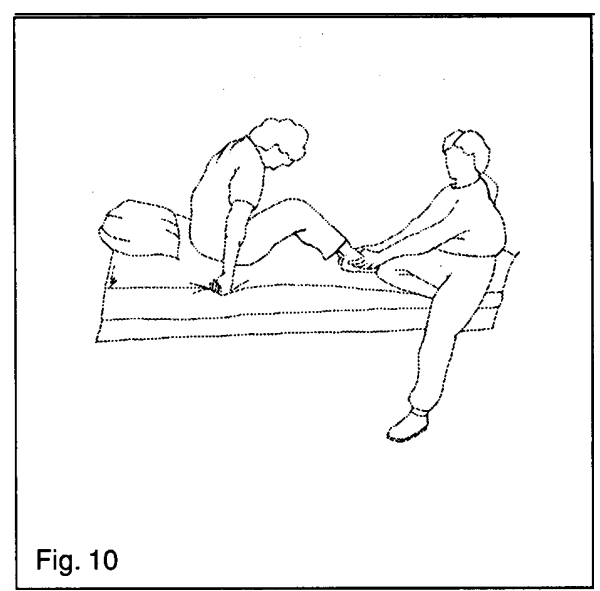

Quando o paciente não pode colaborar, duas pessoas devem realizar o procedimento. Deve-se também usar um

plástico deslizante e procede-se da seguinte maneira (Figuras 11a e 11b):

- As duas pessoas devem ficaruma de cada lado do leito, olhando na mesma direção

- Abaixar a altura da cama, de uma forma tal que os trabalhadores de enfermagem possam colocar um joelho na cama, mantendo a outra perna firmemente no chão

- Segurar a mão do paciente com uma das mãos e agarrar no local apropriado do plástico com a outra

- Usando movimento coordenado, sentar sobre os calcanhares, movendo, ao mesmo, tempo o cliente. Repetir o procedimento, se for necessário

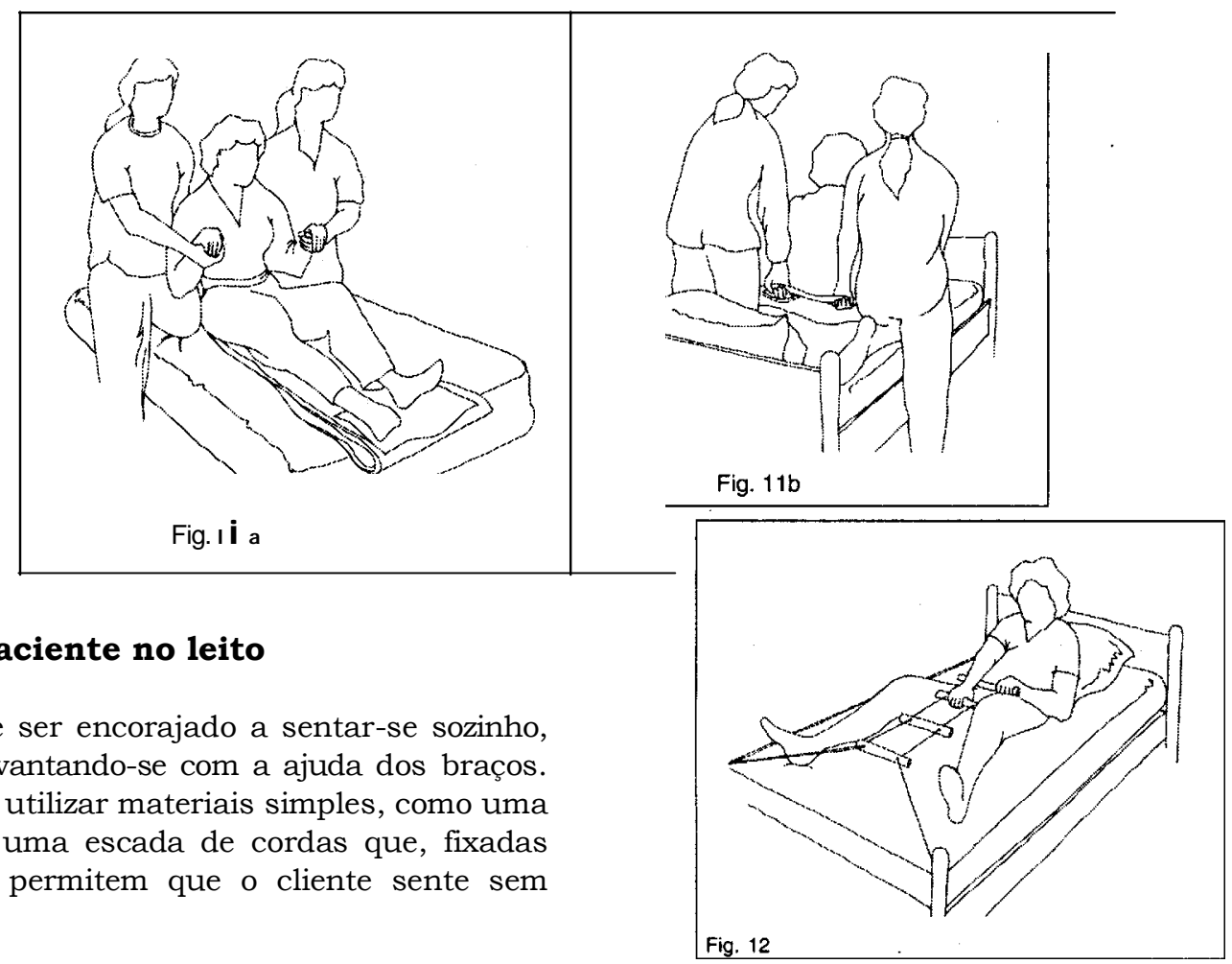


Quando o cliente é auxiliado por outra pessoa, pode-se fazer da seguinte forma (Figuras 13 a e 13b):

- A pessoa fica de frente para o paciente, colocando um dos seus joelhos ao nível do quadril do paciente e sentando-se sobre seu próprio tornozelo

- Segurar no cotovelo do paciente, que também apóia no cotovelo da pessoa. O paciente deve se sentar apoiando-se na pessoa.

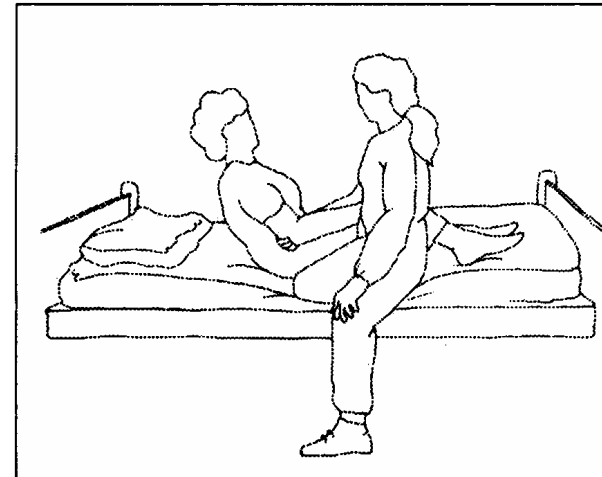

Fig. 13 a

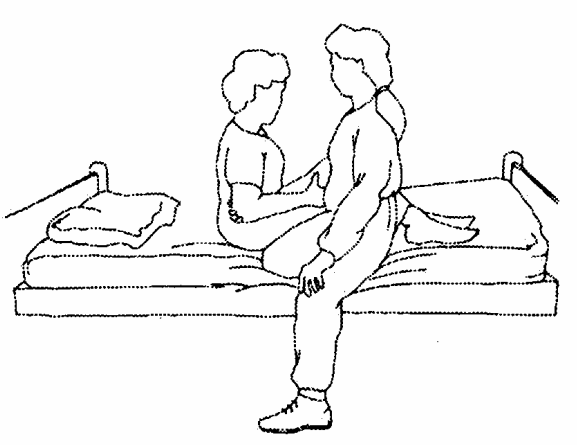

Fig. $13 b$
Se o paciente não consegue auxiliar, uma outra alternativa é realizar o procedimento com duas pessoas, da seguinte maneira (Figura 14):

- Permanecer uma pessoa de cada lado da cama, olhando em direção da cabeceira

- Ficar ajoelhada, mantendo o joelho ao nivel do quadril do cliente

- Segurar nos cotovelos e trazer o paciente para frente, enquanto senta em seus calcanhares. Pode-se usar, como um auxilio nessa manobra, uma toalha resistente, que é colocada nas costas do paciente

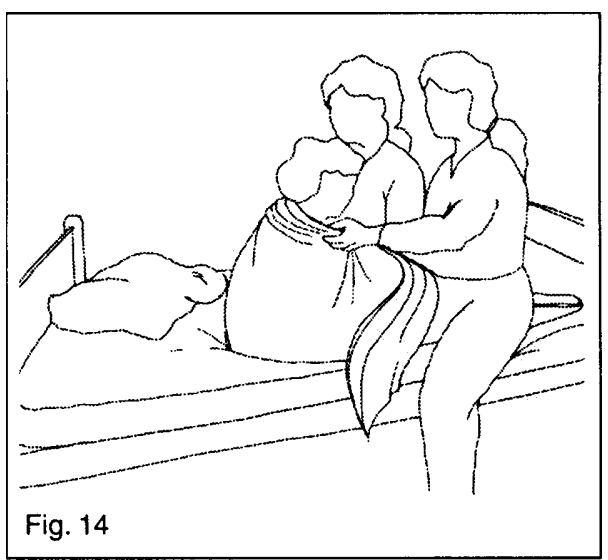

\subsubsection{Sentar o paciente na beira da cama}

No caso do cliente estar deitado, seguir os seguintes passos (Figura 15):

- Colocar o paciente em decúbito lateral, sobre um plástico deslizante, e de frente para o lado em que vai se sentar

- Elevar a cabeceira da cama

- Uma pessoa apóia a região dorsal e o ombro do paciente e a outra segura os membros inferiores

- De uma forma coordenada, elevar e girar o paciente até ele ficar sentado

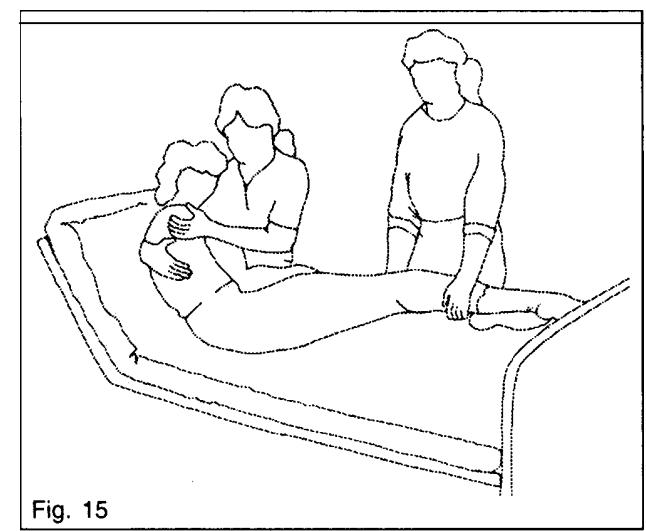

Uma outra alternativa é levantar o paciente, apoiando no cotovelo, como descrito anteriormente, estando o cliente sobre um plástico deslizante. Depois, mover os seus membros inferiores para fora do leito (Figura 16).

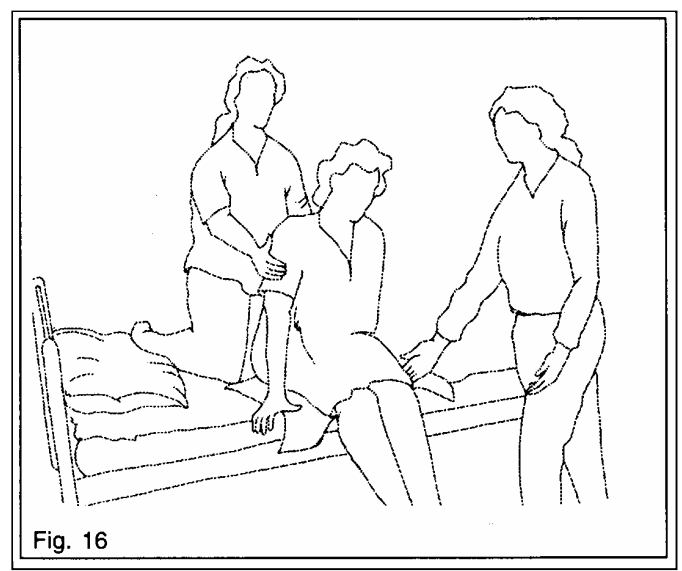

\subsection{Transporte de pacientes}

O transporte de pacientes deve ser realizado com a ajuda de elementos auxiliares, tais como cintos e pranchas de transferência, discos giratórios e auxílios mecânicos. 


\subsubsection{Auxiliar o cliente a levantar de cadeira ou poltrona}

Nesse procedimento, é muito importante selecionar cadeiras ou poltronas de acordo com as necessidades de cada pessoa, levando em consideração a promoção de conforto e independência. Não se deve esquecer também os equipamentos auxiliares, como andadores e bengalas.

Quando o paciente necessita de ajuda, devese usar um cinto de transferência e proceder da seguinte maneira (Figuras 17a e 17b):

- Colocar o cliente para a frente da cadeira, puxando-o alternadamente pelo quadril
- Permanecer ao lado da cadeira, olhando do mesmo lado que o paciente

- O cliente deve colocar uma mão no braço mais distante da cadeira e a outra é apoiada pela mão do trabalhador de enfermagem. Com o outro braço, o trabalhador circunda a cintura do paciente, segurando no cinto de transferência

- Levantar de uma forma coordenada, com movimentos de balanço.

Dependendo das condições do cliente, pode ser necessária a participação de uma outra pessoa, do outro lado da cadeira

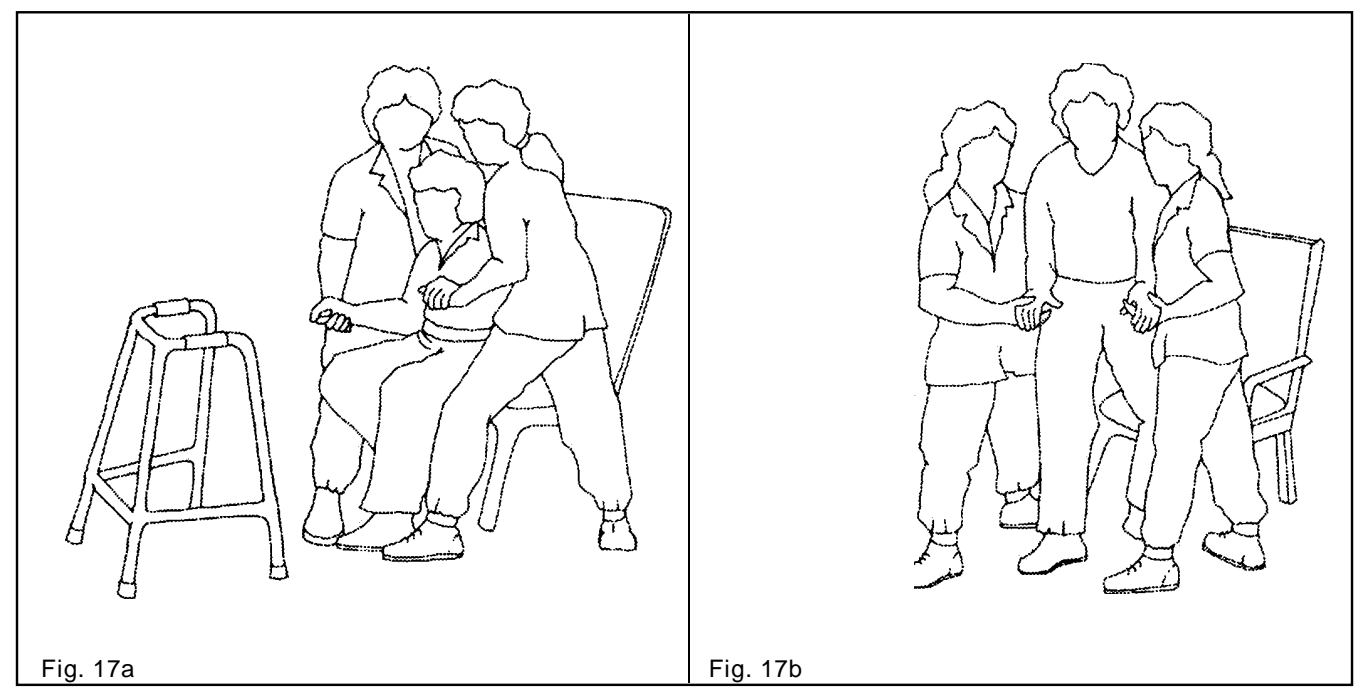

\subsubsection{Auxiliar o cliente a deambular}

É importante fazer uma avaliação cuidadosa para verificar se o cliente tem condições de deambular. A pessoa deve permanecer bem próxima do paciente, do lado em que ele apresenta alguma deficiência, colocando um braço em volta da cintura e o outro apoiando a mão. O ideal, nestes casos, é utilizar um cinto especial, colocado na cintura do paciente (Figura 18).

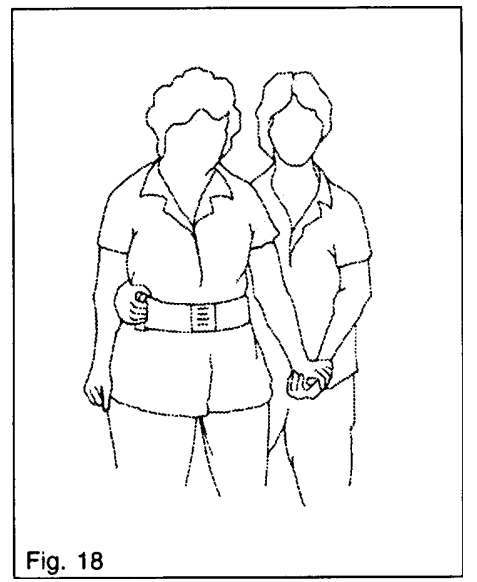

\subsubsection{Transferir o cliente do leito para uma poltrona ou cadeira de rodas}

O paciente pode executar essa transferência de uma forma independente ou com uma pequena ajuda, utilizando uma tábua de transferência, da seguinte maneira (Figuras 19a e 19b):

- Posicionar a cadeira próxima à cama. Elas devem ter a mesma altura

- Travar a cadeira e o leito, remover o braço da cadeira e elevar o apoio dos pés

- Posicionar a tábua apoiada seguramente entre a cama e a cadeira 


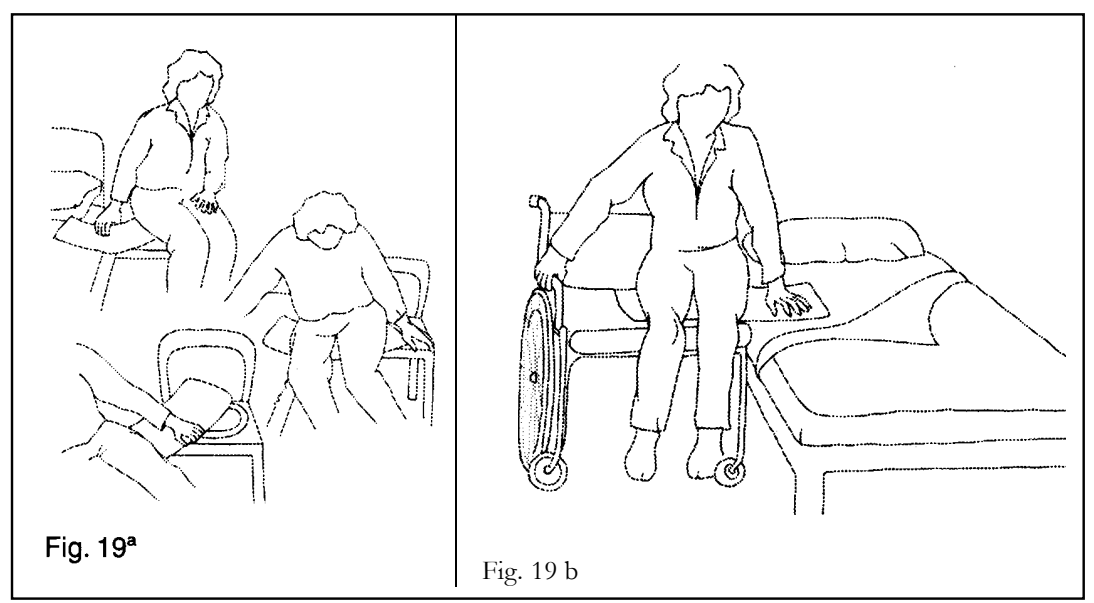

Um outro modo é usar o cinto de transferência, seguindo-se os passos(Figuras 20a, 20b, 20c e 20d):

- Colocar a cadeira ao lado da cama, com as costas para o pé da cama

- Travar as rodas e levantar o apoio para os pés

- Sentar o cliente na beira da cama

- Calçar o cliente com sapato ou chinelo antiderrapante

- Segurar o cliente pela cintura, auxiliando-o a levantar-se, virar-se e sentar-se na cadeira

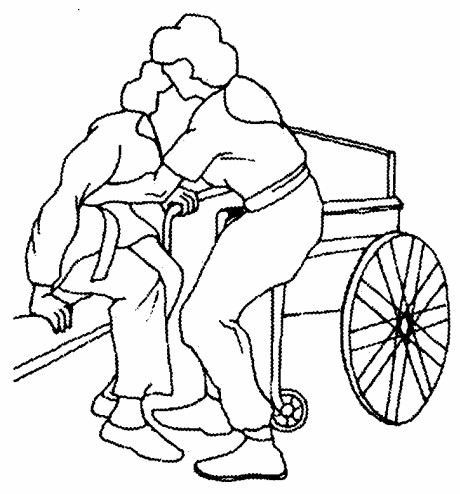

Fig. $20 \mathrm{a}$

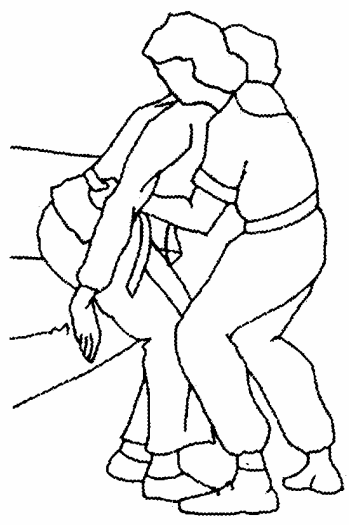

Fig. $20 \mathrm{~b}$

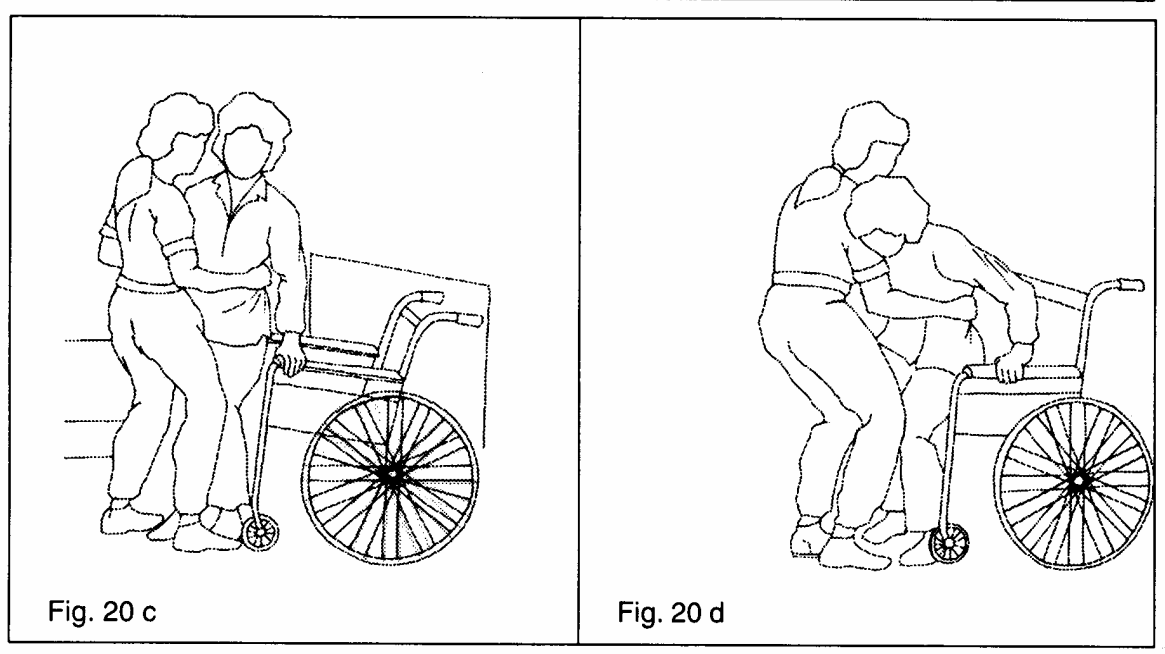

\subsubsection{Trasnferir o paciente do leito para}

\section{um maca}

não existe maneira segura para realizar uma tranferencia manual do leito para uma maca. Existem equipamentos que devem ser utilizados, como as pranchas e os plásticos resistentes de transferências nesse caso, o paciente deve ser virado para que se acomode o material sob ele. .Volta-se o paciente para a posição supina, puxando-o para a maca com a ajuda do material ou do lençol (Figuras 21a e 21b). Devem participar desse procedimento quantas pessoas forem necessárias, dependendo das condições e do peso do cliente. Nunca esquecer de travar as rodas da cama e do leito e de ajustar sua altura. 


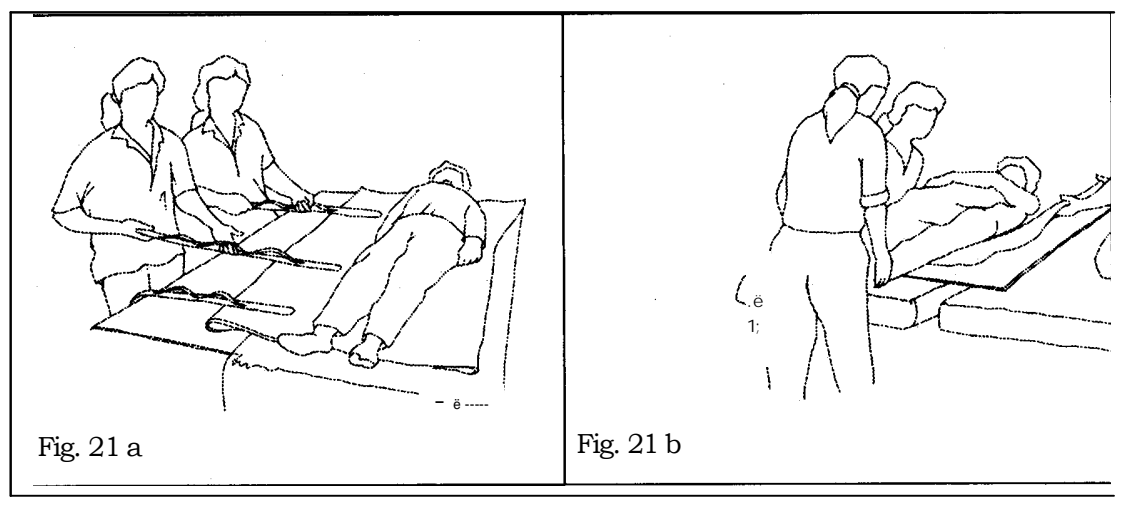

\section{CONSIDERAÇÕES FINAIS}

Organizações e autores internacionais têm procurado despertar a atenção sobre a importância das orientações, com um enfoque ergonômico, sobre os procedimentos de movimentação e transferência de pessoas 1,16,17,22,23,25 . A implementação de treinamentos e reciclagem é parte obrigatória de programas de prevenção de lesões músculo-esqueléticas entre trabalhadores da saúde. Esses procedimentos devem ser aprendidos e praticados de uma forma planejada e sistemática.

Dentro deste contexto, procurou-se colaborar apresentando-se orientações básicas sobre a mobilização e a transferência de clientes dentro de uma abordagem ergonômica.

\section{REFERÊNCIAS BIBLIOGRÁFICAS}

1. ALEXANDRE, N.M.C. Avaliação de determinados aspectos ergonômicos no transporte de pacientes. Ribeirão Preto, 1987. 114p. Dissertação (Mestrado) - Escola de Enfermagem de Ribeirão Preto, Universidade de São Paulo.

2.ALEXANDRE, N.M.C. et al. Aspectos ergonômicos e posturais em centro de material. Rev.Esc.Enf. USP, v. 26, n. 1, p. 87-94,1992.

3. ALEXANDRE, N.M.C. Contribuição ao estudo das cervicodorsolombalgias em profissionais de enfermagem. Ribeirão Preto, 1993. 186p. Tese (Doutorado) - Escola de Enfermagem de Ribeirão Preto, Universidade de São Paulo.

4. ALEXANDRE, N.M.C. et al. Dores nas costas e enfermagem. Rev. Esc. Enf. USP, v. 30. n. 2, p. 267-85, 1996.

5.ARMSTRONG, T.J. et al. Repetitive trauma disorders: job evaluation and design. Human Factors, v. 28, n. 3, p. 325-36, 1986.

6.BARREIRA, T.H.C. Um enfoque ergonômico para as posturas de trabalho. Rev. Bras. Saúde Ocup., v. 17, n. 67, p. 61-71, 1989.

7. BELL, F. Ergonomic aspects of equipament. Int. J. Nurs.

Stud.,

v. 24, n. 4 , p. $331-7,1987$.

8.CHAFFIN, D.B. Occupational biomechanics - a basis for workplace design to prevent musculoskeletal injuries. Ergonomics, v. 30, n. 2, p. 321-9, 1987.

9.COLLINS, J.W. ; OWEN, B.D. NIOSH Research initiatives to prevent back injuries to nursing assistants, aides, and orderlies in nursing homes. Am. J. Ind. Med., v. 29, n. 4, p. 421-24, 1996.

10. DUL, J. ; WEERDMEESTER, B. Ergonomia prática. São Paulo, Edgard Blücher, 1995.
11. FRAGALA, G. Using ergonomics to prevent back injuries. Nurs. Manag., v. 25, n.10, p. 98-100, 1994.

12. GRANDJEAN, E. Fitting the task to the man. 4 ed. London, Taylor \& Francis, 1988.

13. HARBER, P. et al. Importance of non-patient transfer activities in nursing - related back pain. J. Occup. Med., v. 29, n. 12, p. 967-70, 1987.

14. HELLSING, A L. et al. Ergonomic education for nursing students. Int. J. Nurs.Stud., v. 30, n. 6, p. 499-510, 1993.

15. MARZIALE, M.H. P. Condições ergonômicas da situação de trabalho do pessoal de enfermagem em uma unidade de internação hospitalar. Ribeirão Preto, 1995. 163p. Tese (Doutorado)- Escola de Enfermagem de Ribeirão Preto, Universidade de São Paulo.

16. NATIONAL BACK PAIN ASSOCIATION. Royal College of Nursing. The guide to the handling of patients. London, 1997.

17. NATIONAL BACK PAIN ASSOCIATION. A carer's guide to safer moving \& handling of patients. London, 1998.

18. OWEN, B. D. ; GARG, A Back stress isn't part of the job. Amer. J. Nurs., v. 93, n. 2, p. 48-51, 1993.

19. RANIERE, T.M. Prevention of cumulative trauma injuries. AAOHN J., v. 337, n. 6, p. 221-4, 1989.

20. STUBBS, D.A et al. Back pain in the nursing profession. Ergonomics, v. 26, n. 8, p. 755-65, 1983.

21. TROUP, J.D.G. ; RAUHALA, H.H. Ergonomics and training. Int. J. Nurs. Stud., v. 24, n. 4, p. 325-30, 1987.

22. TUGHY-MAIS, K. A manual of handling people: a health and safety guide for carers. Adelaide, Helios Art and Book, 1994.

23. UNIVERSITY OF SURREY. Ergonomics Research Unit. Back pain in nurses: summary and recommendations. Guildford, 1986.

24. VIDEMAN, T. et al. Patient handling skill, back injuries and back pain. Spine, v. 14, n. 2, p. 148-55, 1989.

25. WORLD HEALTH ORGANIZATION. Identification and control of work-related diseases. Geneva, 1985. (Techn. Rep. Ser. 7144).

26. ZELENKA, J. P. et al. Minimal forces to move patients. Am. J. Occup. Ther., v. 50, n. 5, p. 354-61, 1996. 